\title{
Penalty Model of Work Schedule Delay of Program under Contracted Environment Based on Sub-Network
}

\author{
Jingchun $\mathrm{FENG}^{1,4, *}$, DaisongHU ${ }^{1,3,4}$, Yue $\mathrm{ZHANG}^{1,2}$, and Lingli DONG ${ }^{1,2}$ \\ ${ }^{1}$ Business School, Hohai University, Nanjing 210098, P. R. China. \\ ${ }^{2}$ Institute of Project Management, Nanjing 210098, P. R. China. \\ ${ }^{3}$ International River Research Centre, Nanjing 210098, P. R. China. \\ ${ }_{4}^{4}$ Jiangsu Provincial Collaborative Innovation Center of World Water Valley and Water Ecological Civilization, Nanjing 211100, P. R. \\ China
}

\begin{abstract}
Through the sub-network construction and the application of critical path method, this paper analyzes the impact of work schedule delay on the schedule of contracted project itself, the success or contracted projects, other follow-up contracted projects, and the program on the basis of double-code network and related lemmas. Based on this, a penalty model of work schedule delay is constructed and a case study is carried out. The research results show that the penalty model of work schedule delay can effectively deal with the impact of work schedule delay on the whole program under the condition of multiple stakeholders. The research results of this paper are conducive to the real-time control of the schedule of various kinds of work, contracted projects, and the program, and lay a foundation for the improvement of FIDIC penalty conditions (8.7) of contract, the definition of responsibility division within and among contractors, and the analytic processing of claims for contracted projects.
\end{abstract}

\section{Introduction}

Large-scale projects are characterized by many stakeholders, complex relations among stakeholders, long construction period, many uncertain factors, high risks of implementation, strong constraints among contracted projects, and high complexity of organization and coordination. It is difficult to apply the theory and method of schedule management for single-project to large-scale projects management. It can be seen that how to reduce the probability of schedule delay of each contracted project in the program as much as possible has become a key issue of program schedule management. Due to the limitation that the existing research results on project schedule delay mainly focus on the division of singleproject delay responsibility, delay bonus-penalty structure, multi-project schedule delay in non-contracted environment, and less research on work, this paper analyzes the schedule delay impact of work schedule delay on contracted project itself, the success or contracted projects, other follow-up contracted projects, and the program, and studies the penalty problem caused by the work schedule delay to the whole program accordingly. The delay penalty model in this paper can effectively solve the penalty problem of work schedule delay of the contracted project for program based on multiple independent stakeholders, which helps distinguish the delay responsibility between the employer and the contractor of the program, and can comprehensively measure and compensate the loss of the program schedule delay caused by the contractor, so as to motivate the contractor to pay attention to controlling his own contracted projects and the schedule of various work.

Scholars have carried out studies on schedule delay management of single-project and multi-project. Zou et al.(2017)proposed a mixed-integer linear programming method to calculate the penalty amount in view of the situation of schedule delay occurring in multiple repetitive projects at the same time. [1]. Geiger (2017) proposed a solution based on variable neighborhood search and iterative local search for multi-project scheduling with multi-mode and limited resources[2]. Rajeev et al.(2015)attempted to minimize the total weighted penalty amount for project delay based on priority relationship constraints and resource constraints[3]. Elloumi et al. (2017) studied the problem of multi-modal resource constraint project scheduling under the interruption of both renewable and non-renewable resources[4]. Subulan et al. (2020) proposed a novel interval programming and chance constrained optimization based on hybrid solution approach for a fully uncertain, multi-objective and multimode resource investment project scheduling problem (MRIPSP)[5]. Alipouri et al. (2020) addressed resourceconstrained project scheduling problem with mixed uncertainty of randomness and fuzziness (FS-RCPSP). The activity durations are considered to be fuzzy random variables[6]. Ashtiani (2011) introduced a new class of scheduling policies for solving this problem and studied the resource-constrained project scheduling problem with stochastic activity durations[7].

The existing literature shows that the research on

*Corresponding author: feng.jingchun@163.com 
schedule delay management mainly focuses on singleproject schedule delay, multi-project schedule delay under non-contracted environment, and contracted projects schedule delay. However, the schedule delay of program based on the contracted project only considers the interaction between the contracted projects, without considering the impact of various work within the contracted project on the schedule of other contracted projects or program.

In this paper, the sub-project undertaken by each contractor is abstracted into a sub-network to construct a program structure. On this basis, by the critical path method, the paper analyzes the impact of the delay of certain work schedule in the sub-network on the schedule of its sub-network, the successor sub-network, other follow-up sub-network, and program, so as to construct the penalty model of the work schedule delay of program based on the sub-network.

\section{Meanings of Model Symbols and Development of Program Sub-network}

\subsection{Meanings of model symbols}

Meanings of model symbols in this paper are shown in Table 1.

Table 1. Meanings of model symbols

\begin{tabular}{|c|c|}
\hline Symbol & Meaning \\
\hline$W_{1}, W_{2}, W_{3}, \cdots, W_{n}$ & $\begin{array}{l}\text { different contractors (i.e., sub- } \\
\text { network) }\end{array}$ \\
\hline$\left(W_{1}, W_{2}\right),\left(W_{2}, W_{3}\right)$ & $\begin{array}{c}\text { the logical relationship among } \\
\text { different contractors }\end{array}$ \\
\hline$g_{1}, g_{2}, g_{3}, \cdots, g_{m}$ & $\begin{array}{l}\text { work within each contractor (i.e., sub- } \\
\text { network) }\end{array}$ \\
\hline$\left(g_{1}, g_{2}\right),\left(g_{2}, g_{3}\right), \cdots$ & the interrelationship among work \\
\hline$\hat{\mu}$ & the length of path $\mu$ \\
\hline$\mu_{i j}$ & any path through $(i, j)$ \\
\hline$\mu_{k-l}$ & $\begin{array}{l}\text { the path between node }(k) \text { and node } \\
(l)\end{array}$ \\
\hline$\mu^{\nabla}$ & $\begin{array}{l}\text { the longest path (i.e., the critical line) } \\
\text { in the network diagram }\end{array}$ \\
\hline$\mu_{i j}^{\nabla}$ & the longest path through work $(i, j)$ \\
\hline$\mu_{w_{k}}^{*}$ & $\begin{array}{l}\text { the front main chain of the sub- } \\
\text { network sink } w_{k}\end{array}$ \\
\hline$\mu_{i j-w_{k}}^{\nabla}$ & $\begin{array}{l}\text { the longest path through }(i, j) \text { in the } \\
\text { network composed of all predecess or } \\
\text { work of } w_{k}\end{array}$ \\
\hline$E S_{i j}$ & the earliest start time of work $(i, j)$ \\
\hline$E F_{i j}$ & the earliest finish time of work $(i, j)$ \\
\hline$L S_{i j}$ & the latest start time of work $(i, j)$ \\
\hline$L F_{i j}$ & the latest finish time of work $(i, j)$ \\
\hline$T_{i j}$ & duration \\
\hline$E S_{i}$ & the start time of node $(i)$ \\
\hline$L F_{i}$ & the finish time of node $(i)$ \\
\hline $\begin{array}{l}T F_{i j} \\
=L S_{i j}-E S_{i j} \\
=L F_{i j}-E F_{i j}\end{array}$ & the total float of work $(i, j)$ \\
\hline
\end{tabular}

\begin{tabular}{|c|c|}
\hline $\begin{array}{l}F F_{i j} \\
=E S_{j k}-E F_{i j} \\
=E S_{j}-E S_{i}-T_{i j}\end{array}$ & $\begin{array}{l}\text { the free float of work }(i, j) \text {, and } \\
\text { work }(j, k) \text { means back closely } \\
\text { activity of }(i, j)\end{array}$ \\
\hline$F\left(\Delta T_{i j}\right)$ & $\begin{array}{l}\text { the penalty function of } \\
\operatorname{process}(i j) \text { delay } \Delta T_{i j} \text { in sub-network }\end{array}$ \\
\hline$F_{i}$ & $\begin{array}{l}\text { the claim amount (penalty) raised by } \\
\text { the employer against the contractor of } \\
\text { contracted project of the sub-network } \\
\text { for process }(i j) \text { delay }\end{array}$ \\
\hline$F_{i+k}$ & $\begin{array}{l}\text { the claim amount (penalty) raised by } \\
\text { the contractor of the follow-up } \\
\text { contracted projects against the } \\
\text { employer for the delay of the earliest } \\
\text { finish time of the } \mathrm{k}^{\text {th }} \text { follow-up sub- } \\
\text { network caused by process }(i j) \text { delay } \\
\qquad(\mathrm{k}=1,2, \ldots, \mathrm{m})\end{array}$ \\
\hline$F_{t}$ & $\begin{array}{l}\text { the claim amount (penalty) raised by } \\
\text { the employer against the contractor of } \\
\text { contracted project for program } \\
\text { schedule delay caused by process }(i j) \\
\text { delay }\end{array}$ \\
\hline$\delta_{1}$ & $\begin{array}{l}\text { the penalty coefficient of work } \\
\text { schedule delay to the contracted } \\
\text { project itself }\end{array}$ \\
\hline$S_{i}$ & the contract amount of the $i^{\text {th }}$ project \\
\hline$\delta_{2}$ & $\begin{array}{l}\text { the penalty coefficient for the delay of } \\
\text { the follow-up contracted projects }\end{array}$ \\
\hline$S_{i+k}$ & $\begin{array}{l}\text { the contract amount of the }(i+k)^{\text {th }} \\
\text { project }\end{array}$ \\
\hline$\delta_{3}$ & the penalty rate for program delay \\
\hline$S_{t}$ & the contract amount of program \\
\hline
\end{tabular}

\subsection{Development of program sub-network}

In order to achieve integrated management and clarify the responsibilities of different stakeholders for work schedule delay, the sub-network is composed of contracted projects undertaken by contractors in the domain, that is, a sub-network is composed of a contracted project. If there is no network sink or there are multiple sinks in a certain program, other methods should be used to judge the work schedule delay.

The division of the sub-network of the program needs to consider the two-layer constraint relationships among work within contractors and among the different contracted projects. The constraint relationship is represented by a directed graph, as shown in the following formulas:

$$
\begin{gathered}
D=\left(W, Q_{1}\right) \\
W=\left(W_{1}, W_{2}, W_{3}, \cdots, W_{n}\right) \\
Q_{1}=\left\{\left(W_{1}, W_{2}\right),\left(W_{2}, W_{3}\right), \cdots,\left(W_{n-1}, W_{n}\right)\right\} \\
W_{i}=\left(G, Q_{2}\right) \\
G=\left(g_{1}, g_{2}, g_{3}, \cdots, g_{m}\right) \\
D=\left(W, Q_{1}\right) \\
Q_{2}=\left\{\left(g_{1}, g_{2}\right),\left(g_{2}, g_{3}\right), \cdots,\left(g_{m-1}, g_{m}\right)\right\}
\end{gathered}
$$

Since there is a schedule cascade effect among different contracted projects in the program, and each contracted project must be completed within the planned duration, it is necessary to put the sub-network in the program for comprehensive analysis to clarify the schedule relationship among different contractors, so as to 
control and adjust the resources and costs of each contracted project. Assume that the program is composed of $\mathrm{n}$ contractors, and each contractor only undertakes one contracted project. In this case, the program is divided into $\mathrm{n}$ sub-network. Considering the strong correlation among the work within the sub-network and among the subnetwork, the sub-network division mode of the program is shown in Fig.1. Where, $A_{i}, B_{i}, \cdots, H_{i}$ refer to the work in the contracted project, and $a_{i}, b_{i}, \cdots, h_{i}, i \in(1, m)$ refer to theduration of work $A_{i}, B_{i}, \cdots, H_{i}$, etc..

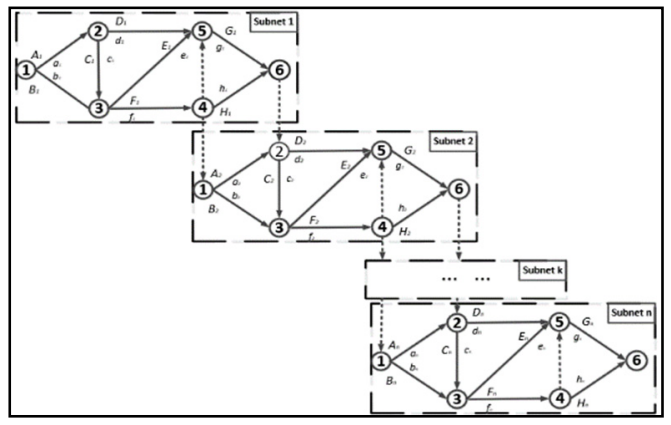

Fig. 1. Sub-network division of program and logical relationship among projects

\section{Analysis of the impact principle of work schedule delay of the program}

\subsection{Basic definitions and lemmas}

The following definitions and lemmas are used as the basis for analyzing the principle of work schedule delay in this paper.

(1) Lemma 1Total float theorem

The total float of certain work is the difference between the length of the critical path and the longest path passing the work, that is, the total float of work is equal to the length of the critical path minus the length of the main line of the work, namely:

$$
\mu_{i j}^{\nabla}=\hat{\mu}^{\nabla}-T F_{i j}
$$

(2) Definition 1Back main chain of sub-network and main line of sub-network

The back main chain of a sub-network refers to the line with the smallest safe float among all the lines between $\operatorname{node}(j)$ and $\operatorname{sink}\left(w_{k}\right)$ in the network composed of all the predecessor work of the $\operatorname{sink}\left(w_{k}\right)$ of the sub-network $k$, which is represented by $\hat{\mu}_{\left(j-w_{k}\right)}^{\oplus}$. The main line of the subnetwork refers to the line formed by the front main chain of certain work $(i, j)$, the back main chain $\hat{\mu}_{\left(j-w_{k}\right)}^{\oplus}$ of the sub-network and work itself in the network composed of all the predecessor work of $\operatorname{sink}\left(w_{k}\right)$ of sub-network $k$, which is represented by $\mu_{\left(i j-w_{k}\right)}^{\nabla}$. At the same time, this line is the longest line passing $(i, j)$ in the network composed of all the predecessor work of $\operatorname{sink}\left(w_{k}\right)$ of sub-network $k$.

(3) Lemma 2 Thetheorem of back main chain of subnetwork

The length of the longest line segment between any node $(j)$ and $\operatorname{sink}\left(w_{k}\right)$ of the sub-network in the sub- network is equal to the difference between the length of the front main chain of $\left(w_{k}\right)$ minus the finish time of the node. This longest line segment is the back main chain of the sub-network of node $\left(w_{k}\right)$, namely:

$$
\hat{\mu}_{\left(j-w_{k}\right)}^{\oplus}=\max \left\{\hat{\mu}_{\left(j-w_{k}\right)}\right\}=\hat{\mu}_{\left(j-w_{k}\right)}^{*}-L F_{j}
$$

(4) Definition 2 The total float of front main chain

The total float of the front main chain refers to the maximum time that the delay time will not cause the change of the front main chain if certain work is delayed in the network composed of all the predecessor work of $\operatorname{sink}\left(w_{k}\right)$ of sub-network $k$, which is represented by $T F_{i j}^{w_{k}}$.

(5) Lemma 3 Total float theorem of front main chain

In CPM network, the total float of the front main chain of the predecessor work $(i, j)$ of a node $w_{i}$ is the length of its front main chain minus the length of the longest line passing $(i, j)$ in the network composed of all the predecessor work of $\left(w_{k}\right)$, namely:

$$
T F_{i j}^{w_{k}}=\mu_{w_{k}}^{*}-\mu_{\left(i j-w_{k}\right)}^{\nabla}
$$

Based on the above definitions and lemmas, the impact principle of the schedule delay of contracted projects of program is analyzed.

\subsection{Analysis of work schedule delay in program}

\subsubsection{Analysis of critical works schedule delay to the delay of the follow-up sub-network}

For any critical work $(i, j)$, if the delay time of schedule is $\Delta T_{i j}\left(\Delta T_{i j}>0\right)$, its impact on follow-up subnetwork $\left(\Delta w_{i}\right)$ is divided into two cases:

For work $(i, j) \in \mu^{\nabla}$, it can be seen from the definition of critical path that the free float of all work on critical path is zero. When $(i, j) \in \mu_{w_{i}}^{*}$, the former main chain $\mu_{w_{i}}^{*}$ of $w_{i}$ passes through $(i, j)$. According to the theorem of the former main chain, at this time, $(i, j)$ delays $\Delta T_{i j}$, and the front main chain of sub-network $w_{i}$ remains the same, but its length increases by $\Delta T_{i j}$, which is $\hat{\mu}_{w_{i}}^{*}=\hat{\mu}_{w_{i}}^{*}+\Delta T_{i j}$, then the duration of the followup sub-network $w_{i}$ delays $\Delta T_{i j}$. When $(i, j) \notin \mu_{w_{i}}^{*}$, the former main chain $\mu_{w_{i}}^{*}$ of $w_{i}$ does not passthrough $(i, j)$.According to the total float theorem of the front mainchain, if $\Delta T_{i j} \in\left[0, T F_{i j}^{w_{i}}\right], \mu_{w_{i}}^{*}$ is still the same, and the follow-up sub-network $w_{i}$ will not have the effect of schedule delay. If $\Delta T_{i j} \in\left(T F_{i j}^{w_{i}},+\infty\right)$, the front main chain changes, and $\hat{\mu}_{w_{i}}^{*}=\mu_{i j}^{* \nabla}+\Delta T_{i j}-T F_{i j}^{w_{i}}$.

According to the above analysis, the impact of the critical work schedule delay on the delay of the follow-up sub-network is as follows:

(1) When $(i, j) \in \mu^{\nabla}$, and $(i, j) \in \mu_{w_{i}}^{*}$,

$$
\Delta w_{i}=\Delta T_{i j}
$$

(2) When $(i, j) \in \mu^{\nabla}$, and $(i, j) \notin \mu_{w_{i}}^{*}$,

$$
\Delta w_{i}=\left\{\begin{array}{l}
0, \Delta T_{i j} \in\left[0, T F_{i j}^{w_{i}}\right] \\
\Delta T_{i j}-T F_{i j}^{w_{i}}, \Delta T_{i j} \in\left(T F_{i j}^{w_{i}},+\infty\right)
\end{array}\right.
$$




\subsubsection{Analysis of non-critical work schedule delay to the delay of the follow-up sub-network}

For any non-critical work $(i, j)$, if the delay time of schedule is $\Delta T_{i j}\left(\Delta T_{i j}>0\right)$, its impact on follow-up subnetwork is as follows:

(1) When the schedule delay time is $\Delta T_{i j} \in\left(0, T F_{i j}\right]$, the original critical path $\mu^{\nabla}$ remains unchanged, and the original critical work of the predecessor sub-network of the sink of sub-network itself and a follow-up sub-network remains unchanged. Therefore, it can be seen that the earliest start time of the sink of the sub-network does not change, so the earliest start time of the follow-up subnetwork sink of $(i, j)$ does not change.

(2) When $\Delta T_{i j} \in\left(T F_{i j},+\infty\right)$, the critical path of the program network changes. The relationship between the critical path $\mu_{i j}^{\prime \nabla}$ after the delay and the length of the original critical path: $\mu_{i j}^{\prime \nabla}=\hat{\mu}_{i j}^{\nabla}+\Delta T_{i j} \geq \hat{\mu}_{i j}^{\nabla}+T F_{i j}=$ $\hat{\mu}^{\nabla}$.The earliest start time of the critical work on the follow-up sub-network of work $(i, j)$ is delayed by $\Delta T_{i j}-T F_{i j}$, so it can be seen that the earliest start time of the sub-network sink is delayed by $\Delta T_{i j}-T F_{i j}$.

(3) According to the above analysis, the impact of noncritical work schedule delay on the delay of the follow-up sub-network is as follows:

$$
\Delta w_{i}=\left\{\begin{array}{l}
0, \Delta T_{i j} \in\left(0, T F_{i j}\right] \\
\Delta T_{i j}-T F_{i j}, \Delta T_{i j} \in\left(T F_{i j},+\infty\right)
\end{array}\right.
$$

\subsubsection{Analysis of work schedule delay to the delay of sub-network itself}

For the impact of the delay of any work $(i, j)$ on contracted project (sub-network) itself, since only the duration of the sub-network where the work is located is considered, and the duration of the program is not considered, the sub-network of the contracted project can be separately formed into a small network diagram, which is only used for discussion of its own delay. The total float of network diagram of $\operatorname{work}(i, j)$ itself is expressed as $T F_{i j}^{\prime}$.

For any work $(i, j) \notin \mu^{\nabla}$, since the impact of work $(i, j)$ on the delay of the sink of follow-up sub-network has been given in formulas (11), (12), and (13), based on the analysis of the project contractor's own interests, the subnetwork can be independently analyzed. It can be seen from the total float theorem that the impact on the subnetwork itself is judged based on the float of the subnetwork itself when work $(i, j) \notin \mu^{\nabla}$ delays $\Delta T_{i j}$.

According to the above analysis, the impact of work schedule delay on the delay of the sub-network itself is as follows:

$$
\Delta w_{i}=\left\{\begin{array}{l}
0, \Delta T_{i j} \in\left[0, T F_{i j}^{\prime}\right) \\
\Delta T-T F_{i j}^{\prime}, \Delta T_{i j} \in\left[T F_{i j}^{\prime},+\infty\right)
\end{array}\right.
$$

\section{Developing penalty model of work schedule delay for program based on sub-network}

\subsection{Modeling ideas}

The development of the penalty model of work schedule delay for program based on sub-network should fully consider three parts of the penalty: the first one is the penalty for the delay caused by the schedule of the contracted project itself; the second one is the penalty for the delay caused by the schedule of the successor contracted projects and other follow-up contracted projects; and the third one is the penalty for the delay caused by the schedule of program. The steps to establish the penalty model for work schedule delay of program are as follows:

(1) According to the logical relationship and duration among the contracted projects and among the work in program, the activity-on-arrow network is drawn.

(2) Calculate the time parameters of the program work, including the earliest start time, the earliest finish time, the latest start time, the latest finish time, the total float, the free float and the safe float, and determine the planned duration and critical path of the program.

(3) Each contracted project is divided into a subnetwork, and six time parameters of each sub-network are calculated.

(4) Determine the last work of the sub-network, that is, the front main chain, the back main chain, and the main line of the sink of the sub-network.

(5) One is calculated according to the original time parameters and logical relationships; the other is calculated according to the relationship between the actual delay time and the total float and the float of the front main chain of the sub-network.

(6) According to the relevant conditions of the contract, the penalty coefficient and delay days are determined, and the penalty model is constructed.

\subsection{Assumptions}

The relevant assumptions of this study are as follows:

(1) In the program, the contracted projects are undertaken by different contractors, that is, one contractor only undertakes one contracted project.

(2) When the work schedule of a contracted project is delayed, the contractor of the contracted project does not confront crashing.

(3) The duration of the program and the contracted projects shall not be advanced.

(4) The impact of work schedule delay in parallel contracted projects is not considered. As there may be two or more parallel contracted projects in the program, this situation will become more complex, which is not discussed in this paper.

(5) The planned duration of program and contracted project is equal to the calculated duration. 


\subsection{Construction of penalty model for work schedule delay in program}

\subsubsection{Penalty model for critical work schedule delay}

When the critical work of the sub-network of the contracted project is delayed, it will affect the schedule of the successor contracted projects, other follow-up contracted projects, and the program. At this time, the impact of the delay on the program schedule can be judged according to the total float, while the impact on the finish time of the follow-up contracted projects can be judged according to the total float of the sub-network depending on whether the contracted project is on the front main chain of the sub-network. Therefore, the penalty amount for the delay of critical work caused by the contractor includes three parts: first, the penalty amount for the delay of the contracted project itself; second, the penalty amount for delay of the successor contracted projects and other follow-up contracted projects; and third, the penalty amount of program schedule delay, namely:

$$
F\left(\Delta T_{i j}\right)=F_{i}+F_{i+k}+F_{t}
$$

1. The penalty function of schedule delay caused by critical work schedule delay to contracted project itself is as follows:

$$
F_{i}=\delta_{1} \cdot \Delta w_{i} \cdot S_{i}
$$

Substituting the value of $\Delta w_{i}$ into formula (16), we can get:

$$
F_{i}=\left\{\begin{array}{l}
0, \Delta T_{i j} \in\left[0, T F_{i j}^{\prime}\right] \\
\delta_{1} \cdot\left(\Delta T_{i j}-T F_{i j}^{\prime}\right) \cdot S_{i}, \Delta T_{i} \in\left(T F_{i j}^{\prime},+\infty\right)
\end{array}\right.
$$

2. The penalty function of schedule delay caused by critical work schedule delay to the successor contracted projects and other follow-up contracted projects is as follows:

$$
F_{i+k}=\delta_{2} \cdot \Delta w_{i+k} \cdot S_{i+k}
$$

The value of $\Delta w_{i+k}$ is substituted into formula (18), which needs to be analyzed according to whether the delayed work is located on the front main chain of $w_{i+k}$ :

(1) If the delayed work is located on the front main chain of the sub-network $w_{i+k}$, the delay penalty function is as follows:

$$
F_{i+k}=\delta_{2} \cdot \Delta T_{i j} \cdot S_{i+k}
$$

(2) When the delay time is greater than the total float of the front main chain of the sub-network, the duration of the follow-up sub-network will be affected, thus resulting in delay penalty. At this time, the penalty function of work schedule delay is as follows:

$$
F_{i+k}=\left\{\begin{array}{l}
0, \Delta T_{i j} \in\left[0, T F_{i j}^{w_{i+k}}\right] \\
\delta_{2} \cdot\left(\Delta T_{i j}-T F_{i j}^{w_{i+k}}\right) \cdot S_{i+k}, \Delta T_{i j} \in\left(T F_{i j}^{w_{i+k}},+\infty\right)
\end{array}\right.
$$

3. The penalty function of program schedule delay caused by critical work schedule delay is as follows:

$$
F_{t}=\left\{\begin{array}{l}
0, \Delta T_{i j} \in\left[0, T F_{i j}\right] \\
\delta_{3} \cdot\left(\Delta T_{i j}-T F_{i j}\right) \cdot S_{t}, \Delta T_{i j} \in\left(T F_{i j},+\infty\right)
\end{array}\right.
$$

To sum up, the penalty function for the delay of critical work schedule caused by the contractor is as follows:

$$
F\left(\Delta T_{i j}\right)=\delta_{1} \cdot \Delta w_{i} \cdot S_{i}+\delta_{2} \sum_{k=1}^{m}\left[\left(2^{n}-1\right) \Delta w_{i+k} \cdot\right.
$$

$\left.S_{i+k}\right]+\delta_{2} \sum_{k=1}^{m}\left(n \cdot \Delta w_{i+k}^{\prime} \cdot S_{i+k}\right)+\delta_{3} \cdot \Delta w_{t} \cdot S_{t}(22)$

When process $(i j)$ is located on the front main chain of $w_{i+k}, \mathrm{n}=0$, and the calculation base $\Delta w_{i+k}$ of delay time is $\Delta T_{i j}$. When process $(i j)$ is not located on the front main chain of $w_{i+k}, \mathrm{n}=1$, and the calculation base $\Delta w_{i+k}$ of delay time is $\Delta T_{i j}-T F_{i j}^{w_{i+k}}$.

\subsubsection{Penalty model for non-critical work schedule delay}

The impact of the non-critical work schedule delay of the sub-network on the duration of its successor sub-network, other follow-up sub-network, and program is discussed in the following two cases:

1. When $\Delta T_{i j} \in\left(0, T F_{i j}\right]$, that is, the delay time of work schedule is not greater than the total float, the original critical work of predecessor sub-network of sinks of the sub-network itself, the successor sub-network and other follow-up sub-network will not change. Therefore, the delay of non-critical work schedule will affect neither the duration of program nor the finish time of the successor sub-network and other follow-up sub-network. At this time, the penalty amount only considers the penalty amount $F_{i}$ of the schedule delay of sub-network itself, and the penalty function of delay is:

$$
F_{i}=\delta_{1} \cdot \Delta w_{i} \cdot S_{i}
$$

When the delay time of non-critical work schedule is less than the total float, the penalty function of the contracted project is:

$$
F\left(\Delta T_{i j}\right)=\delta_{1} \cdot \Delta w_{i} \cdot S_{i}
$$

Substituting the value of $\Delta w_{i}$ into the formula, we can get:

$$
\begin{aligned}
& F\left(\Delta T_{i j}\right) \\
& =\left\{\begin{array}{l}
0, \Delta T_{i j} \in\left[0, T F_{i j}^{\prime}\right] \\
\delta_{1} \cdot\left(\Delta T_{i j}-T F_{i j}^{\prime}\right) \cdot S_{i}, \Delta T_{i} \in\left(T F_{i j}^{\prime}, T F_{i j}\right)
\end{array}\right.
\end{aligned}
$$

2. When $\Delta T_{i j} \in\left(T F_{i j},+\infty\right)$, that is, the delay time of work schedule is greater than the total float, the original critical work of predecessor sub-network of sinks of the sub-network itself, the successor sub-network and other follow-up sub-network will change. The delay of noncritical work not only affects the overall duration of the program, but also affects the duration of its successor subnetwork and other follow-up sub-network.

(1) The penalty function of the impact of non-critical work schedule delay on the schedule of the sub-network itself has been given in the above analysis.

(2) The penalty function of the impact of non-critical work schedule delay on the schedule of its successor subnetwork and other follow-up sub-network is as follows:

$$
F_{i+k}=\delta_{2} \cdot \Delta w_{i+k} \cdot S_{i+k}
$$

Substituting the value of $\Delta w_{i+k}$ into the formula, we can get:

$$
F_{i+k}=\delta_{2} \cdot\left(\Delta T_{i j}-T F_{i j}\right) \cdot S_{i+k}
$$

(3) The penalty function of the impact of non-critical work schedule delay on program schedule is as follows:

$$
F_{t}=\delta_{3} \cdot \Delta w_{t} \cdot S_{t}
$$

Substituting the value of $\Delta w_{t}$ into the formula, we can get:

$$
F_{t}=\delta_{3} \cdot\left(\Delta T_{i j}-T F_{i j}\right) \cdot S_{t}
$$

According to the above analysis, when the delay time of non-critical work schedule is greater than the total float, 
the penalty function of the contractor is:

$$
\begin{gathered}
F\left(\Delta T_{i j}\right)=\delta_{1} \cdot \Delta w_{i} \cdot S_{i}+\delta_{2} \sum_{k=1}^{m} \Delta w_{i+k} \cdot S_{i+k}+\delta_{3} . \\
\Delta w_{t} \cdot S_{t}(30)
\end{gathered}
$$

To sum up, the penalty function for the delay of noncritical work schedule caused by the contractor is as follows:

$$
\begin{gathered}
F\left(\Delta T_{i j}\right)= \\
\left\{\begin{array}{l}
\delta_{1} \cdot \Delta w_{i} \cdot S_{i}, \Delta T_{i j} \in\left(0, T F_{i j}\right] \\
\delta_{1} \cdot \Delta w_{i} \cdot S_{i}+\delta_{2} \sum_{k=1}^{m} \Delta w_{i+k} \cdot S_{i+k}+\delta_{3} \cdot \Delta w_{t} \cdot S_{t}, \Delta T_{i j} \in\left(T F_{i j},+\infty\right)
\end{array}\right.
\end{gathered}
$$

(31)

\section{Conclusions}

The main research conclusions are as follows:

(1) Since the penalty of work schedule delay in the program considers the impact of work schedule delay on the duration of the contracted project itself, the successor contracted projects, other follow-up contracted projects, and program, the penalty amount of work schedule delay calculated according to the model in this paper can truly reflect the impact degree of work schedule delay on the whole program.

(2) The penalty model constructed in this paper is applicable to both a single contracted project and program, that is, it is applicable to both the employer and the contractor. With the help of the penalty model, the employer can calculate the penalty amount for the impact of the work schedule delay caused by the contractor on the whole program, and the contractor can calculate the loss caused by the non-contractor reasons.

\section{Acknowledgement}

The authors are grateful to the Office of the South-toNorth Water Diversion Project Construction Committee under the State Council. This research was supported by the National Social Science Fund(Grant No. 17BGL156): Research on the socialized supervision mechanism of market subjects in the engineering construction, and by Postgraduate Research \& Practice Innovation Program of Jiangsu Province(KYCX17_0511).

\section{References}

1. Zou X., Fang S. C., Huang Y. S., Zhang L. H., J. Manage. Eng, 31, 6016003 (2017)

2. Geiger, M.J., European Journal of Operational Research, 256, 729 (2017)

3. Rajeev S., Kurian S., Paul B. International Journal of Information \& Decision Sciences, 7 (2015)

4. Elloumi, S., Fortemps, P., and Loukil, T. Computers \& Industrial Engineering, 106,161 (2017)

5. Subulan, K., Expert Systems with Applications, 149,113189. (2020)

6. Alipouri, Y. Sebt, M.H. Ardeshir, A. \& Zarandi, M.H.F., Operational Research, 20,197 (2020)

7. Ashtiani, B. Leus, R. Aryanezhad, M.B., Journal of Scheduling.14,157 (2011) 